\title{
A population-based analysis of leaving the hospital against medical advice: incidence and associated variables
}

\author{
Allen Kraut ${ }^{1,2^{*}}$, Randy Fransoo ${ }^{2,3}$, Kendiss Olafson ${ }^{1}$, Clare D Ramsey ${ }^{1,2}$, Marina Yogendran ${ }^{3}$ and Allan Garland ${ }^{1,2,3}$
}

\begin{abstract}
Background: Prior studies of patients leaving hospital against medical advice (AMA) have been limited by not being population-based or assessing only one type of patient.

Methods: We used administrative data at the Manitoba Centre for Health Policy to evaluate all adult residents of Manitoba, Canada discharged alive from acute care hospitals between April 1, 1990 and February 28, 2009. We identified the rate of leaving AMA, and used multivariable logistic regression to identify socio-demographic and diagnostic variables associated with leaving AMA.

Results: Of 1916104 live hospital discharges, 21417 (1.11\%) ended with the patient leaving AMA. The cohort contained 610187 individuals, of whom 12588 (2.06\%) left AMA once and another 2986 (0.49\%) left AMA more than once. The proportion of AMA discharges did not change over time. Alcohol and drug abuse was the diagnostic group with the highest proportion of AMA discharges, at $11.71 \%$. Having left AMA previously had the strongest association with leaving AMA (odds ratio 170, 95\% confidence interval 156-185). Leaving AMA was more common among men, those with lower average household incomes, histories of alcohol or drug abuse or HIV/AIDS. Major surgical procedures were associated with a much lower chance of leaving the hospital AMA.

Conclusions: The rate of leaving hospital AMA did not systematically change over time, but did vary based on patient and illness characteristics. Having left AMA in the past was highly predictive of subsequent AMA events.
\end{abstract}

Keywords: Against medical advice, Epidemiology, Canada, Population based

\section{Background}

Between $1-2 \%$ of hospitalized patients [1-4] leave hospital against medical advice (AMA). The proportion has varied with study location and diagnosis, ranging from $0.6 \%$ in rural hospitals [5] to $13 \%$ in inner city hospitals [6], and from $0.1 \%$ among postpartum patients [7] to $51 \%$ for people in an anorexia nervosa inpatient treatment program [8]. The variable having the strongest reported association with leaving AMA is having done so before $[5,6,9,10]$. Other variables associated with leaving AMA have been younger age, male sex, membership in a visible minority, lower socioeconomic status, absence of health

\footnotetext{
* Correspondence: allen.kraut@med.umanitoba.ca

${ }^{1}$ Department of Internal Medicine, University of Manitoba Winnipeg,

Manitoba, Canada

${ }^{2}$ Department of Community Health Sciences, University of Manitoba

Winnipeg, Manitoba, Canada

Full list of author information is available at the end of the article
}

insurance, substance abuse, psychiatric disorders, and urban residency [1-7,9-17].

We have recently shown using a large population based dataset, that leaving AMA is associated with increased hospital readmissions and mortality at all times up to 180 days post discharge [18] building on limited previous work $[4,9,14,19]$. As there is little understanding of what is responsible for these adverse outcomes, identification of patients at high risk of leaving AMA is important in determining the cause of these poor outcomes and in the design of interventions to try and offset them.

The major limitations of the existing studies on leaving AMA are that most were based on localized experiences with limited numbers and follow-up, [5,6,10,14,20] were limited to one type of admission diagnosis, $[4,7,9,12,13,16,17,19,20]$ or were not population based

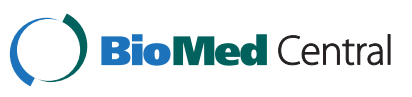


[1,3]. Many studies also did not adjust for confounding variables. The objective of this research was to address these limitations by utilizing a large, population-based data system containing comprehensive information about patients, their diseases, and their hospitalizations to identify variables independently associated with leaving hospital AMA.

\section{Methods}

We used administrative hospital abstract data collected by the Department of Health of the Canadian province of Manitoba, housed in de-identified form at the Manitoba Centre for Health Policy (MCHP). Manitoba has a population of 1.2 million; its two urban areas contain $61 \%$ of the population. The government-funded health care system covers all provincial residents. The administrative data contains comprehensive health-related information, and have been linked to other data including census-based socioeconomic information, and vital status. MCHP data has been used and validated extensively to study a wide range of medical outcomes [21,22].

All Manitoba residents $\geq 18$ years of age, discharged alive after admission to provincial acute care hospitals from April 1, 1990 to February 28, 2009 were identified. Because a patient can undergo inter-hospital transfer within a single episode of hospital care, we identified two abstracts as representing a transfer and therefore part of a single hospital episode if: (i) hospital entry of the later abstract was within one calendar day of the previous hospital separation, and (ii) an acute care hospital was the "discharge to" location of the earlier abstract, and/or the "admitted from" location of the later abstract. The exception was that two hospital abstracts were considered as separate hospital episodes if the earlier one indicated that the patient left AMA. Same day surgeries were not considered admissions in this dataset.

In Manitoba, hospital abstracts are collected in each hospital by centrally trained data abstractors using uniform definitions, data collection methods, and data entry software. A specific discharge code for AMA is used. Episodes of care were designated as AMA or non-AMA depending on the presence of this code in the last hospital abstract of each hospital episode.

Age, sex, hospital, fiscal year of admission, and postal code of residence were obtained from the first hospital abstract for each episode of hospital care. Fiscal years run from April 1st to the following March 31st and will be referred to by the calendar year of the start of the period. Length of stay was calculated from the admission and discharge dates and times of the hospital episode. Whether the individual had a prior AMA discharge during the five years before the current admission was also identified.

Socioeconomic status (SES) was based on average household income within geographic dissemination areas, based on the 2001 Canadian census; in Manitoba these area-level census tracts contain an average of 550 persons. These were separately divided into quintiles for rural and urban residents, with 1 being the lowest and 5 the highest income quintile. People living in areas where the Canadian census does not calculate an average household income formed an eleventh SES category called "not calculated" (NC). Most people in the NC category are residents in nursing homes, other chronic care facilities, or penitentiaries.

Diagnosis was derived from the "Most Responsible Hospital Diagnosis" [23] i.e. the diagnosis responsible for the majority of the hospital stay, obtained from the final hospital abstract of each hospital episode. Diagnoses were initially grouped into the 18 main ICD-9-CM chapter headings [24]. Headings with low counts were collapsed, and specific diagnostic entities of interest were extracted from major headings; for a total of 23 diagnoses or diagnostic categories. The only discharges that were excluded were the small number of hospital episodes that lacked discharge diagnoses.

Whether the hospital episode included a major surgical procedure was identified. From 2004 onwards, this information was based on Canadian reporting standards for hospital abstracts, the Case Mix Group (CMG) system. Before 2004, it was based on the similar Diagnosis Related Groups system [25,26].

Hospitals were categorized into: the three urban tertiary hospitals in Manitoba, the four urban community hospitals grouped together, and the rural hospitals grouped together. To assess for changes over time, years were groups as: 1990-1993, 1994-1998, 1999-2003, and 2004-2008.

For co-morbidities, the 31 conditions described by Elixhauser et al. [27] were identified from all diagnoses in the hospital discharge abstracts, using the coding described by Quan et al. [28]. For this purpose we included the index hospitalization and all hospital diagnoses for all hospitalizations within one year backwards in time $[29,30]$. Although the 31 conditions separately codified diabetes with and without chronic complications, in our data these two were not accurately distinguished prior to 2006, so the two subcategories were collapsed together.

We performed external validation of the AMA designation in the administrative data, using 291 hospital abstracts where true AMA status was identified by reading the final nurse and physician progress notes in the hospital charts. These charts were chosen in an approximate 1:2 ratio of AMA:nonAMA as indicated by independently acquired data used by our Department of Medicine. All 198 patients who did not leave AMA were correctly identified as such in the abstracts (specificity 100\%, 95\% C.I., 98.2$100 \%)$. However, only 81 of 93 patients who left AMA were correctly coded in the abstracts as having done so (sensitivity 87\%, 95\% C.I., 78.5-93.2\%). In such a cohort, 
the indication of AMA status in the hospital abstracts would have a positive predictive value of $100 \%$, and a negative predictive value of $99.86 \%$.

To identify independent factors independently associated with patients leaving the hospital AMA, we constructed multivariable logistic regression models. Independent variables were the hospital diagnosis, comorbidities, sex, age, hospital type, time period, SES, and whether a major surgical procedure was performed. Anticipating that having left AMA before would have such a strong association with subsequently going AMA that it might confound analysis of other factors, two multivariable regression models are presented -- one including and the other excluding an independent variable representing whether patients had any prior AMA episodes.

Though the unit of measure for this analysis was individual episodes of hospital care, these are not all independent since many individuals had multiple episodes. To account for this clustering of data, we used General Estimating Equations (GEE) [31], with an exchangeable correlation structure and robust (empirical) standard errors. We assessed for multicollinearity among the independent variables using the variance inflation factor, with values under 4 considered acceptable [32]. We report parameter estimates from these models as odds ratios (OR) with $95 \%$ confidence intervals ( $95 \% \mathrm{CI}$ ). We compared regression models using the QIC parameter for GEE models, where lower values indicate a better fit [33].

An important issue in dealing with clustered data is that independent variables may have different between-person and within-person associations with the outcome. We allowed for this in the regressions by considering two separate versions of independent variables [34,35]. For example, the coefficient of the within-person age variable indicates how the probability of leaving AMA varied with age for a given person; the coefficient of the betweenperson age variable indicates the difference in probability of leaving AMA between different people of different ages, each of whom had a single hospitalization. For most of the independent variables only the between-individual version of the variable was included. However, both versions were included for age, and whether the hospitalization included a major surgical procedure.

Univariate comparisons were done using Chi-square tests and t-tests, as appropriate. All analyses were done using SAS version 9.1 (SAS Institute, Cary, NC). A p-value of 0.05 was considered significant.

This proposal was approved by the Research Ethics Board of the University of Manitoba and the Health Information Privacy Committee of the Manitoba Government.

\section{Results}

We identified 1916104 hospital episodes in which patients were discharged alive during the 19 year study period, of which 21417 (1.11\%) ended with the patient leaving hospital AMA. This cohort contained 610187 individuals of whom 12588 (2.06\%) left AMA once, and $2986(0.49 \%)$ left AMA more than once. Thus, $19.1 \%$ of people who ever left hospital AMA did so more than once, accounting for $41.2 \%$ of all AMA events. The largest number of AMA episodes for one individual was 39. Median length of stay was five days (interquartile range (IQR) 3-9 days) for non-AMA hospital episodes and three days for AMA episodes (IQR 2-6 days) ( $\mathrm{p}<0.001$ ).

There was a marked decline in yearly hospital episodes over time, while the percentage of episodes ending with patients leaving AMA fluctuated in an undulating pattern (Figure 1). The slight decline in total hospital episodes observed in the final study year is due to the fact that this period only included 11 months.

Table 1 compares the proportion of hospital episodes ending in an AMA discharge by patient and illness characteristics. Men, and individuals under age 50, had higher proportions of AMA discharges. The association of SES was different for urban and rural residents with a stronger gradient of increasing AMA discharges with lower SES being observed for urban residents. The AMA discharge proportion was also higher for rural hospitals, and for one of the tertiary care hospitals. Individuals who had major surgical procedures were less likely to leave AMA.

The hospital diagnosis grouping with the highest percentage of AMA discharges was alcohol and drug abuse, at $11.71 \%$ (Table 2). Poisoning had an AMA discharge proportion of $7.54 \%$. Alcohol and drug abuse accounted for $13.54 \%$ of all of the AMA discharges. Complications of childbirth and the puerperium, although having a relatively low AMA discharge proportion of $0.63 \%$, contributed $10.4 \%$ of the total number of AMA discharges due to the high number of admissions for this diagnostic grouping.

Of the two multivariable GEE regression models for leaving AMA (Table 3), the one including a past history of leaving AMA provided a better fit compared to the model excluding that variable (QIC 169829.0 vs. 200911.2). This reflects that having had any prior AMA events had by far the strongest association with future AMA events (OR 170, 95\% CI 156-185). Indeed, its inclusion led to a diminished influence of numerous other variables; for example, the co-morbidity HIV/AIDS was not associated with leaving AMA when the prior AMA variable was included in the model (OR 0.93, 95\% CI 0.521.67), but was strongly associated when the prior AMA variable was not included (OR 2.85, 95\% CI 2.04-4.04). Since including the prior AMA variable masks the association with other relevant characteristics, and because of issues with interpreting the prior AMA variable for patients without any past hospitalizations, for identifying other variables 


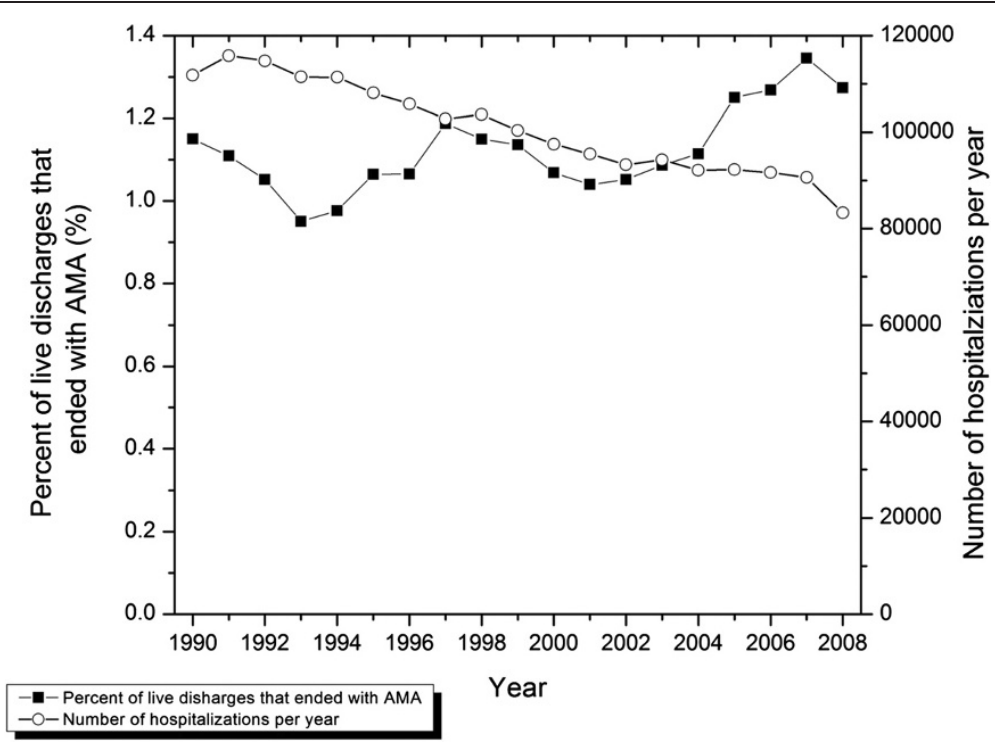

Figure 1 Total discharges and percentage AMA discharges in Manitoba, Canada. April 1, 1990 to February 28, 2009.

associated with leaving AMA we emphasize the model excluding the prior AMA variable (Table 3, left half).

There were no consistent changes in the odds of leaving AMA across the 19 year evaluation period. While older patients were less likely to leave AMA than were younger patients, the odds that a given patient would leave AMA did not change as that person aged. Men were more likely to leave AMA. Consistent gradients with SES showed that individuals living in areas with lower average household incomes were more likely to leave AMA. There were some differences between hospitals in the odds of patients leaving AMA, with the highest OR being for the rural hospitals.

A number of chronic conditions were significantly associated with an elevated risk of leaving AMA; most prominent among these were alcohol abuse (OR 3.82; 95\% CI 3.56-4.11), HIV/AIDS (OR 2.87; 95\% CI 2.044.04) and drug abuse (OR 2.19; 95\% CI 1.99-2.42). The two co-morbid conditions which conferred the lowest odds for leaving AMA, were hypothyroidism (OR 0.70; 95\% CI 0.57-0.86) and uncomplicated hypertension (OR 0.74; 95\% CI 0.67-0.81).

The chance of leaving AMA varied substantially with the main hospital diagnosis. Compared to the reference group of cardiovascular disorders, the ORs varied 10fold, from 0.27 to 2.72. All but three of the 22 diagnoses were significantly different than the reference group. Prominent among those more likely to leave AMA were patients with poisonings or overdoses related to medications or alcohol (OR 2.72; 95\% CI 2.25-3.28), intracranial injuries without skull fracture (OR 2.10; 95\% CI 1.692.61) and tuberculosis (OR 2.02; 95\% CI 1.46-2.79). Among those with the lowest chance of leaving AMA were patients admitted with problems relating to pregnancy and childbirth (OR 0.27; 95\% CI 0.24-0.32), and cancer (OR 0.52; 95\% CI 0.47-0.64). Finally, major surgical procedures were associated with a much lower chance of leaving the hospital AMA; this was true both between different people, and comparing between different hospitalizations for a given person.

\section{Discussion}

Using a large, population-based database including all acute hospital admissions among adults over a 19 year period, we found that just over $1 \%$ of hospital episodes discharged alive ended with the patient leaving AMA. This fraction did not change systematically over the study period; with the declining rate of hospitalizations over this 19 year period (Figure 1), this translates to a decline over time in the absolute numbers of AMA events per year. As our data does not include information about patients' reasons for leaving AMA, it does not allow us to further explore whether there were temporal changes in those reasons.

Approximately $20 \%$ of people who left AMA did so multiple times, accounting for over $40 \%$ of all AMA events. Studying these individuals may be useful to identify steps that could be taken during hospitalization to limit the chance of them leaving AMA again.

Our modeling showed that having left AMA from a prior hospitalization had by far the strongest association with future AMA events; indeed it masked the effect of numerous other relevant variables. Since characteristics relating to an person's tendency to leave AMA are for the most part present for all of that his/her hospitalizations, the prior AMA variable itself includes some of 
Table 1 Proportion of live hospital discharges that left against medical advice (AMA), Manitoba, Canada; 1990-2009

\begin{tabular}{|c|c|c|}
\hline Parameter & $\begin{array}{c}\text { Percentage AMA } \\
\text { discharges }\end{array}$ & $\begin{array}{c}\text { Number of } A M A \\
\text { discharges }\end{array}$ \\
\hline All episodes & 1.11 & 21417 \\
\hline \multicolumn{3}{|l|}{ Sex } \\
\hline Male & 1.50 & 10789 \\
\hline Female & 0.89 & 10628 \\
\hline \multicolumn{3}{|l|}{ Age } \\
\hline $18-34$ & 1.61 & 8654 \\
\hline $35-49$ & 1.96 & 6136 \\
\hline $50-64$ & 1.06 & 3478 \\
\hline $65+$ & 0.42 & 3149 \\
\hline \multicolumn{3}{|l|}{ Income quintile } \\
\hline Urban 1st quintile (lowest) & 2.22 & 5831 \\
\hline Urban 2nd quintile & 1.10 & 2250 \\
\hline Urban 3rd quintile & 0.83 & 1557 \\
\hline Urban 4th quintile & 0.60 & 913 \\
\hline Urban 5th quintile (highest) & 0.45 & 598 \\
\hline Rural 1st quintile (lowest) & 1.67 & 3864 \\
\hline Rural 2nd quintile & 1.00 & 2147 \\
\hline Rural 3rd quintile & 0.78 & 1534 \\
\hline Rural 4th quintile & 0.86 & 1393 \\
\hline Rural 5th quintile (highest) & 0.85 & 1058 \\
\hline Not calculated* & 0.57 & 272 \\
\hline \multicolumn{3}{|l|}{ Admitting Hospital } \\
\hline Urban tertiary care hospital 1 & 1.70 & 5680 \\
\hline Urban tertiary care hospital 2 & 0.65 & 1939 \\
\hline Urban tertiary care hospital 3 & 0.92 & 1030 \\
\hline Urban community hospitals & 0.82 & 4030 \\
\hline Rural hospitals & 1.28 & 8738 \\
\hline \multicolumn{3}{|l|}{ Major surgical procedure group. } \\
\hline Non-surgical & 1.44 & 19367 \\
\hline Surgical & 0.36 & 2050 \\
\hline
\end{tabular}

*Includes postal codes for which average household income was not calculated, primarily including institutions such as nursing homes, other chronic care facilities and prisons.

those other individual characteristics, in effect "absorbing" their independent influence on the tendency to leave AMA again. Omitting the prior AMA variable from the model eliminates this sort of confounding, and permits clearer identification of other variables associated with leaving AMA.

Those other independent variables associated with leaving AMA included younger age, male sex, lower SES, various comorbid conditions and hospital admission diagnoses, and nonsurgical status. Among admission diagnoses associated with a lower odds of leaving AMA were neoplasia
Table 2 Most responsible hospital diagnosis associated with leaving against medical advice (AMA) discharges, Manitoba, Canada; 1990-2009

\begin{tabular}{|c|c|c|c|}
\hline $\begin{array}{l}\text { Most responsible hospital } \\
\text { diagnosis }\end{array}$ & $\begin{array}{c}\text { Total } \\
\text { number of } \\
\text { episodes }\end{array}$ & $\begin{array}{c}\text { AMA episode, } \\
\text { (\% of live } \\
\text { discharges) }\end{array}$ & $\begin{array}{c}\% \text { of total } \\
\text { AMA } \\
\text { episodes }\end{array}$ \\
\hline Alcohol or drug abuse & 24768 & $2900(11.71)$ & 13.54 \\
\hline $\begin{array}{l}\text { Poisonings by pharmaceuticals } \\
\text { or alcohol }\end{array}$ & 9684 & $730(7.54)$ & 3.41 \\
\hline Alcohol-related liver disease & 2202 & $162(7.36)$ & 0.76 \\
\hline Diabetic ketoacidosis & 4728 & $267(5.65)$ & 1.25 \\
\hline Tuberculosis & 1353 & $69(5.10)$ & 0.32 \\
\hline $\begin{array}{l}\text { Intracranial injuries without } \\
\text { skull fracture }\end{array}$ & 4759 & $216(4.54)$ & 1.01 \\
\hline Injuries with open wounds & 10636 & $443(4.17)$ & 2.07 \\
\hline $\begin{array}{l}\text { Mental disorders except } \\
\text { alcohol and drug abuse }\end{array}$ & 82349 & $1745(2.12)$ & 8.15 \\
\hline $\begin{array}{l}\text { Skin and subcutaneous } \\
\text { tissue disorders }\end{array}$ & 26340 & $522(1.98)$ & 2.44 \\
\hline $\begin{array}{l}\text { Symptoms, signs and } \\
\text { ill-defined conditions }\end{array}$ & 102434 & $1595(1.56)$ & 7.45 \\
\hline $\begin{array}{l}\text { Endocrine, metabolic, } \\
\text { nutritional, immune disorders } \\
\text { except diabetic ketoacidosis }\end{array}$ & 40787 & $633(1.55)$ & 2.96 \\
\hline $\begin{array}{l}\text { Infectious diseases except } \\
\text { tuberculosis }\end{array}$ & 17965 & $242(1.35)$ & 1.13 \\
\hline Trauma, injury and poisoning* & 117929 & $1473(1.25)$ & 6.88 \\
\hline Respiratory disorders & 138875 & $1445(1.04)$ & 6.75 \\
\hline Hematologic disorders & 13591 & $129(0.95)$ & 0.60 \\
\hline $\begin{array}{l}\text { Digestive disorders except } \\
\text { alcohol-related liver conditions }\end{array}$ & 215693 & $2034(0.94)$ & 9.50 \\
\hline Neurologic disorders & 41637 & $332(0.80)$ & 1.55 \\
\hline Circulatory disorders & 251132 & $1921(0.76)$ & 8.97 \\
\hline Musculoskeletal system disorders & 91921 & $607(0.66)$ & 2.83 \\
\hline $\begin{array}{l}\text { Complications of pregnancy, } \\
\text { childbirth and the puerperium }\end{array}$ & 355735 & $2227(0.63)$ & 10.40 \\
\hline Genitourinary disorders & 115034 & $697(0.61)$ & 3.25 \\
\hline $\begin{array}{l}\text { All other diagnoses and } \\
\text { categories }\end{array}$ & 127860 & $670(0.52)$ & 3.15 \\
\hline Neoplasms & 118692 & $358(0.30)$ & 1.67 \\
\hline Totals: & 1916104 & $21417(1.11)$ & 100.0 \\
\hline
\end{tabular}

which may be associated with a more significant disease burden, congenital anomalies which may be associated with more significant mental or physical impairments making leaving AMA difficult, and conditions associated with pregnancy which may have typical shorter lengths of stay. Two novel findings that extend beyond prior work were also observed. First, the likelihood that a given patient would leave AMA did not change as that person aged. This indicates that whatever predisposes people to leave AMA does not change as they age. The second observation was a much 
Table 3 Results of logistic regression models for leaving hospital against medical advice (AMA)

\begin{tabular}{|c|c|c|c|c|}
\hline & \multicolumn{2}{|c|}{ Excluding prior AMA variable } & \multicolumn{2}{|c|}{ Including prior AMA variable } \\
\hline & Odds ratio & $95 \% \mathrm{Cl}$ & Odds ratio & $95 \% \mathrm{Cl}$ \\
\hline \multicolumn{5}{|l|}{ Between-individual parameters } \\
\hline Age (per decade) & $0.73^{*}$ & $0.72,0.74$ & $0.82^{*}$ & $0.80,0.83$ \\
\hline Male sex & $1.21^{*}$ & $1.16,1.26$ & $1.48^{*}$ & $1.41,1.55$ \\
\hline Prior AMA event & - & - & $170.0^{*}$ & $156.2,185.1$ \\
\hline \multicolumn{5}{|c|}{ Socioeconomic status (5th [highest] urban quintile as reference group) } \\
\hline Urban 1st quintile (lowest) & $3.58^{*}$ & $3.21,3.99$ & $2.54^{*}$ & $2.28,2.83$ \\
\hline Urban 2nd quintile & $2.07^{*}$ & $1.84,2.33$ & $1.78^{*}$ & $1.58,2.00$ \\
\hline Urban 3rd quintile & $1.64^{*}$ & $1.45,1.86$ & $1.41^{*}$ & $1.24,1.59$ \\
\hline Urban 4th quintile & $1.20+$ & $1.05,1.38$ & 1.13 & $0.99,1.30$ \\
\hline Rural 1st quintile (lowest) & $2.48^{*}$ & $2.19,2.79$ & $1.88^{*}$ & $1.66,2.13$ \\
\hline Rural 2nd quintile & $1.49^{*}$ & $1.31,1.69$ & $1.33^{*}$ & $1.16,1.52$ \\
\hline Rural 3rd quintile & $1.30^{*}$ & $1.14,1.49$ & $1.20 \neq$ & $1.05,1.38$ \\
\hline Rural 4th quintile & $1.39^{*}$ & $1.22,1.59$ & $1.20 \neq$ & $1.04,1.38$ \\
\hline Rural 5th quintile (highest) & $1.33^{*}$ & $1.16,1.52$ & $1.29+$ & $1.13,1.47$ \\
\hline Not calculated $\S$ & $1.49^{*}$ & $1.25,1.79$ & $1.61^{*}$ & $1.33,1.94$ \\
\hline \multicolumn{5}{|c|}{ Hospital (urban community hospitals as reference group) } \\
\hline Urban tertiary hospital 1 & $1.18^{*}$ & $1.10,1.26$ & 1.07 & $1.00,1.15$ \\
\hline Urban tertiary hospital 2 & $0.87 \dagger$ & $0.80,0.94$ & $0.85 \dagger$ & $0.78,0.92$ \\
\hline Urban tertiary hospital 3 & $0.84 \dagger$ & $0.76,0.93$ & $0.76^{*}$ & $0.68,0.85$ \\
\hline Rural hospitals & $1.25^{*}$ & $1.16,1.35$ & 0.96 & $0.88,1.05$ \\
\hline \multicolumn{5}{|l|}{ Chronic co-morbid conditions } \\
\hline Alcohol abuse & $3.82^{*}$ & $3.56,4.11$ & $1.39^{*}$ & $1.24,1.55$ \\
\hline HIV/AIDS & $2.87^{*}$ & $2.04,4.04$ & 0.93 & $0.52,1.67$ \\
\hline Drug abuse & $2.19^{*}$ & $1.99,2.42$ & 0.85 & $0.73,1.00$ \\
\hline Weight loss & $1.93^{*}$ & $1.40,2.64$ & $1.70 \neq$ & $1.12,2.60$ \\
\hline Blood loss anemia & $1.68+$ & $1.25,2.27$ & 1.01 & $0.67,1.51$ \\
\hline Diabetes & $1.52^{*}$ & $1.41,1.64$ & 0.97 & $0.88,1.07$ \\
\hline Deficiency anemia & $1.38^{*}$ & $1.13,1.68$ & 0.80 & $0.60,1.05$ \\
\hline Peripheral vascular disease & $1.36+$ & $1.15,1.61$ & 0.92 & $0.77,1.11$ \\
\hline Fluid and electrolyte disorders & $1.34^{*}$ & $1.18,1.53$ & $0.64^{*}$ & $0.52,0.79$ \\
\hline Valvular disease & $1.29 \neq$ & $1.05,1.59$ & 1.01 & $0.79,1.29$ \\
\hline Liver disease & $1.26 \neq$ & $1.09,1.45$ & 0.87 & $0.70,1.09$ \\
\hline Other neurological disorders & $1.24^{*}$ & $1.11,1.37$ & $0.75+$ & $0.63,0.88$ \\
\hline Peptic ulcer disease without bleeding & 1.24 & $0.95,1.61$ & 0.69 & $0.46,1.04$ \\
\hline Chronic pulmonary disease & $1.23^{*}$ & $1.12,1.36$ & $0.84 \neq$ & $0.75,0.95$ \\
\hline Paralysis & $1.21 \neq$ & $0.98,1.49$ & 0.79 & $0.59,1.06$ \\
\hline Coagulopathy & 1.20 & $0.94,1.53$ & $0.62 \ddagger$ & $0.43,0.90$ \\
\hline Hypertension, complicated & 1.09 & $0.85,1.39$ & 0.78 & $0.58,1.04$ \\
\hline Obesity & 1.09 & $0.92,1.30$ & 0.99 & $0.79,1.25$ \\
\hline Congestive heart failure & 1.07 & $0.96,1.20$ & 0.96 & $0.85,1.09$ \\
\hline Renal failure & 1.06 & $0.90,1.26$ & 0.82 & $0.68,1.00$ \\
\hline Solid tumor without metastasis & 1.04 & $0.85,1.27$ & $0.81 \neq$ & $0.67,0.99$ \\
\hline Rheumatoid arthritis/collagen-vascular disorders & 1.04 & $0.86,1.26$ & 0.87 & $0.70,1.07$ \\
\hline
\end{tabular}


Table 3 Results of logistic regression models for leaving hospital against medical advice (AMA) (Continued)

\begin{tabular}{|c|c|c|c|c|}
\hline Metastatic cancer & 0.96 & $0.81,1.14$ & $0.84 \neq$ & $0.71,1.00$ \\
\hline Lymphoma & 0.91 & $0.67,1.23$ & 0.85 & $0.65,1.11$ \\
\hline Depression & $0.89 \neq$ & $0.80,0.99$ & $0.52^{*}$ & $0.45,0.62$ \\
\hline Psychoses & $0.87 \neq$ & $0.76,1.00$ & $0.60^{*}$ & $0.49,0.72$ \\
\hline Pulmonary circulation disorders & 0.85 & $0.62,1.17$ & 0.74 & $0.51,1.07$ \\
\hline Arrhythmia & $0.81 \dagger$ & $0.72,0.91$ & $0.69^{*}$ & $0.60,0.78$ \\
\hline Hypertension, uncomplicated & $0.74^{*}$ & $0.67,0.81$ & $0.78^{*}$ & $0.70,0.86$ \\
\hline Hypothyroidism & $0.70+$ & $0.57,0.86$ & $0.80 \neq$ & $0.64,1.00$ \\
\hline \multicolumn{5}{|c|}{ Most responsible hospital diagnosis (cardiovascular disorders as reference group) } \\
\hline Poisoning by pharmaceuticals or alcohol & $2.72^{*}$ & $2.25,3.28$ & $4.16^{*}$ & $3.31,5.23$ \\
\hline Intracranial injuries without skull fracture & $2.10^{*}$ & $1.69,2.61$ & $3.34^{*}$ & $2.64,4.23$ \\
\hline Tuberculosis & $2.02^{*}$ & $1.46,2.79$ & 1.39 & $0.88,2.20$ \\
\hline Alcohol or drug abuse & $1.91^{*}$ & $1.65,2.20$ & $2.69^{*}$ & $2.25,3.21$ \\
\hline Injuries with open wounds & $1.91^{*}$ & $1.62,2.26$ & $1.71^{*}$ & $1.39,2.12$ \\
\hline Diabetic ketoacidosis & $1.69+$ & $1.24,2.30$ & $0.59 \neq$ & $0.38,0.92$ \\
\hline Diseases of the skin and subcutaneous tissue & $1.44^{*}$ & $1.21,1.72$ & $1.37 \neq$ & $1.11,1.68$ \\
\hline Symptoms, signs, and ill-defined conditions & $1.31+$ & $1.14,1.50$ & 1.08 & $0.91,1.28$ \\
\hline Injury and poisoning|| & $1.14 \ddagger$ & $1.01,1.29$ & $1.27 \dagger$ & $1.11,1.45$ \\
\hline Alcohol-related liver disease & 1.06 & $0.72,1.56$ & $1.92 \neq$ & $1.02,3.63$ \\
\hline Endocrine, metabolic, nutritional, immune disorders" & 1.05 & $0.85,1.29$ & 0.86 & $0.62,1.19$ \\
\hline Mental disorders $^{* *}$ & 0.96 & $0.82,1.13$ & $1.22 \neq$ & $1.01,1.48$ \\
\hline Diseases of the digestive system ${ }^{\dagger+}$ & $0.86 \neq$ & $0.76,0.97$ & $0.62^{*}$ & $0.54,0.72$ \\
\hline Diseases of the musculoskeletal system \& connective tissue & $0.84 \neq$ & $0.71,1.00$ & $0.67^{*}$ & $0.56,0.80$ \\
\hline Diseases of the respiratory system & $0.83 \neq$ & $0.72,0.96$ & $0.82 \neq$ & $0.69,0.96$ \\
\hline Infectious and parasitic diseases except tuberculosis & $0.61 \dagger$ & $0.46,0.79$ & 0.79 & $0.58,1.08$ \\
\hline Diseases of nervous system and sense organs & $0.59^{*}$ & $0.47,0.73$ & $0.58^{*}$ & $0.45,0.74$ \\
\hline Diseases of blood and blood-forming organs & $0.58+$ & $0.38,0.87$ & $0.62 \neq$ & $0.39,0.99$ \\
\hline Diseases of the genitourinary system & $0.56^{*}$ & $0.47,0.65$ & $0.45^{*}$ & $0.38,0.54$ \\
\hline Neoplasms & $0.52^{*}$ & $0.42,0.64$ & $0.61^{*}$ & $0.50,0.75$ \\
\hline $\begin{array}{l}\text { Factors influencing health status, congenital abnormalities, } \\
\text { or conditions originating in the perinatal period }\end{array}$ & $0.38^{*}$ & $0.33,0.45$ & $0.47^{*}$ & $0.40,0.56$ \\
\hline Complications of pregnancy, childbirth, puerperium & $0.27^{*}$ & $0.24,0.30$ & $0.33^{*}$ & $0.29,0.38$ \\
\hline Major surgical procedure & $0.30^{*}$ & $0.28,0.32$ & $0.39^{*}$ & $0.36,0.43$ \\
\hline \multicolumn{5}{|l|}{ Time period (1990-93 as reference group) } \\
\hline 1994-1998 & 0.96 & $0.90,1.03$ & $0.82^{*}$ & $0.76,0.89$ \\
\hline 1999-2003 & $0.91+$ & $0.86,0.97$ & $0.91 \neq$ & $0.84,0.98$ \\
\hline $2004-2008$ & 0.99 & $0.93,1.05$ & 1.03 & $0.96,1.11$ \\
\hline \multicolumn{5}{|c|}{ Within-individual parameters } \\
\hline Age (per decade) & 1.02 & $0.97,1.07$ & 1.01 & $0.96,1.07$ \\
\hline Major surgical procedure & $0.32^{*}$ & $0.30,0.34$ & $0.32^{*}$ & $0.30,0.34$ \\
\hline
\end{tabular}

* $p<0.0001$.

$+p \geq 0.0001$ and $<0.001$

$\neq \mathrm{p} \geq 0.001$ and $<0.05$.

$\S$ Includes postal codes for which average household income was not calculated, primarily institutions such as nursing homes, other chronic care facilities and prisons.

|| Except for intracranial injuries without skull fracture, injuries with open wounds, and poisonings by pharmaceuticals or alcohol.

I Except for diabetic ketoacidosis.

** Except for alcohol or drug abuse.

†† Except for alcohol-related liver disease. 
lower rate of leaving AMA following hospitalizations that included a major surgical procedure in both the betweenand within-individual analyses. Surgical procedures may have lower AMA discharges as many are elective and have early discharge goals. When a surgical procedure is not involved, an individual may feel that they can manage outside the hospital earlier than their caregivers and choose to leave AMA if they have other characteristics associated with AMA discharges.

Substance abuse and HIV/AIDS were strongly associated with leaving AMA, consistent with previous research $[3-5,7,9,10,15,20]$. Addictions and other risktaking behaviors may be related to these associations. Furthermore, individuals with these conditions may not have a primary care physician, which has been associated with leaving AMA $[9,12]$.

In our cohort, one of the tertiary urban hospitals, and the rural hospitals had higher odds ratios for patients leaving AMA, while the other two tertiary urban hospitals had lower ones. This could reflect either hospital factors which influence the likelihood of patients leaving AMA, or systematic differences between patients at the different hospitals that are not captured by the individual-level characteristics included in our analysis. Hospital factors such as size, location, and measures of care, have previously been associated with AMA discharges $[1,3,15,16]$. Our results differ from those of Ibrahim et al. [3] in that we found AMA discharges to be more likely from rural hospitals.

Our study has important strengths. The most notable is that it is a large study that included all adult hospitalizations over a 19 year span in an entire Canadian province. Accordingly, unlike prior studies of leaving AMA, our analysis covered an entire population and included patients with medical, mental health, and surgical problems. We also validated the AMA discharge designation which was used, and adjusted for the potential confounding effect of individuals that have multiple hospitalizations. The main limitations of our study relates to its generalizability; since leaving AMA could be influenced by cultural, religious and other social factors, our results may not apply elsewhere. Although Manitoba has a large Aboriginal population, and prior studies have shown that ethnicity is associated with leaving AMA [2,20], our administrative data does not allow identification of Aboriginal individuals. In addition, we lacked information about the severity of acute illness during hospitalization, admission source, and a variety of social and personal factors such as marital status that could have influenced the AMA decision. Finally, we have no information on physician related variables, which may influence whether some discharges are classified as AMA [36].

\section{Conclusions}

In this study we identified patient and illness factors associated with patients who leave the hospital against medical advice. Identifying patients at risk of leaving AMA is an important step in designing approaches to limiting AMA admissions. Future research is needed in identifying the appropriate ways to deal with patients who leave AMA, to promote high quality care for this population, and to alleviate the potential adverse consequences of this type of discharge [36].

\section{Competing interests}

All authors have also completed the Unified Competing Interest form developed by the International Committee of Medical Journal Editors (ICMJE), available on request from the corresponding author.

\section{Authors' contributions}

AK conceived of the study. All authors oversaw the studies design, contributed to the interpretation of the data, and redrafted the paper for important intellectual content. All authors have approved the final version of the manuscript.

\section{Acknowledgements}

The authors had funding support from the Health Sciences Center Research Foundation and the Manitoba Health Research Council for preparation of the submitted work

The researchers were independent of the studies funders and had full access to all required data. The study funders had no role in the design of the study or in the collection, analysis, and interpretation of data, the writing of the article or the decision to submit it for publication. Although the original data used in this manuscript was collected by Manitoba Health, the results and conclusions presented are those of the authors. No official endorsement by Manitoba Health is intended or should be inferred.

The authors wish to acknowledge Dr. Arjuna Ponnampalam for performing the chart audit for the validation study.

\section{Author details}

${ }^{1}$ Department of Internal Medicine, University of Manitoba Winnipeg, Manitoba, Canada. ${ }^{2}$ Department of Community Health Sciences, University of Manitoba Winnipeg, Manitoba, Canada. ${ }^{3}$ Manitoba Centre for Health Policy, University of Manitoba Winnipeg, Manitoba, Canada.

Received: 25 January 2013 Accepted: 10 October 2013

Published: 14 October 2013

\section{References}

1. Smith DB, Telles JL: Discharges against medical advice at regional acute care hospitals. Am J Public Health 1991, 81:212-215.

2. Franks $P$, Meldrum S, Fiscella K: Discharges against medical advice: are race/ethnicity predictors? J Gen Intern Med 2006, 21:955-960.

3. Ibrahim SA, Kwoh CK, Krishnan E: Factors associated with patients who leave acute-care hospitals against medical advice. Am J Public Health 2007, 97:2204-2208.

4. Glasgow JM, Vaughn-Sarrazin M, Kaboli PJ: Leaving against medical advice (AMA): risk of 30-day mortality and hospital readmission. J Gen Intern Med 2010, 25:926-929.

5. Seaborn MH, Osmun WE: Discharges against medical advice: a community hospital's experience. Can J Rural Med 2004, 9:148-153.

6. Anis AH, Sun H, Guh DP, Palepu A, Schechter MT, O'Shaughnessy MV: Leaving hospital against medical advice among HIV-positive patients. CMAJ 2002, 167:633-637

7. Fiscella K, Meldrum S, Franks P: Post partum discharge against medical advice: who leaves and does it matter? Matern Child Health J 2007, 11:431-436.

8. Woodside DB, Carter JC, Blackmore E: Predictors of premature termination of inpatient treatment for anorexia nervosa. Am J Psychiatry 2004, 161:2277-2281.

9. Weingart SN, Davis RB, Phillips RS: Patients discharged against medical advice from a general medicine service. J Gen Intern Med 1998, 13:568-571.

10. Baptist AP, Warrier I, Arora R, Ager J, Massanari RM: Hospitalized patients with asthma who leave against medical advice: characteristics, reasons, and outcomes. J Allergy Clin Immunol 2007, 119:924-929.

11. Corley MC, Link K: Men patients who leave a general hospital against medical advice: mortality rate within six months. J Stud Alcohol 1981, 42:1058-1061.

12. Jeremiah J, O'Sullivan P, Stein MD: Who leaves against medical advice? J Gen Intern Med 1995, 10:403-405. 
13. Saitz R, Ghali WA, Moskowitz MA: Characteristics of patients with pneumonia who are discharged from hospitals against medical advice. Am J Med 1999, 107:507-509.

14. Hwang SW, Li J, Gupta R, Chien V, Martin RE: What happens to patients who leave hospital against medical advice? CMAJ 2003, 168:417-420.

15. Brook M, Hilty DM, Liu W, Hu R, Frye MA: Discharge against medical advice from inpatient psychiatric treatment: a literature review. Psychiatr Serv 2006, 57:1192-1198.

16. Onukwugha EC, Shaya FT, Saunders E, Weir MR: Ethnic disparities, hospital quality, and discharges against medical advice among patients with cardiovascular disease. Ethn Dis 2009, 19:172-178.

17. Tawk R, Freels S, Mullner R: Associations of mental, and medical illnesses with against medical advice discharges: the national hospital discharge survey, 1988-2006. Adm Policy Ment Health 2013, 40:124-132.

18. Garland A, Ramsey CD, Fransoo R, Olafson K, Chateau D, Yogendran M, et al: Rates of readmission and death associated with leaving hospital against medical advice: a population-based study. CMAJ 2013, 185:1207-1214.

19. Onukwugha E, Mullins CD, Loh FE, Saunders E, Shaya FT, Weir MR: Readmissions after unauthorized discharges in the cardiovascular setting. Med Care 2011, 49:215-224.

20. Fiscella $K$, Meldrum S, Barnett S: Hospital discharge against advice after myocardial infarction: deaths and readmissions. Am J Med 2007, 120:1047-1053.

21. Roos LL, Gupta S, Soodeen RA, Jebamani L: Data quality in an information-rich environment: Canada as an example. Can J Aging 2005, 24(Suppl 1):153-170.

22. Roos NP, Roos LL, Brownell M, Fuller EL: Enhancing policymakers' understanding of disparities: relevant data from an information-rich environment. Milbank Q 2010, 88:382-403.

23. Canadian Institute for Health Information: DAD resource intensity weights and expected length of stay. Ottawa, Ontario; 2005.

24. Centers for Medicare and Medicaid Services: ICD-9CM Official guideliens for coding and reporting. Washington DC: United States Department of Health and Human Services; 2005.

25. Averill RF, Mullin RL, Steinback BA, Elai ED: Diagnosis Related Groups, Version 9.0 Definition Manual. Washington DC: 3M Health Information System; 1991.

26. Canadian Institute For Health Information: CMG + Tool Kit. Ottawa, Ontario; 2007.

27. Elixhauser A, Steiner C, Harris DR, Coffey RM: Comorbidity measures for use with administrative data. Med Care 1998, 36:8-27.

28. Quan H, Sundararajan V, Halfon P, Fong A, Burnand B, Luthi JC, et al: Coding algorithms for defining comorbidities in ICD-9-CM and ICD-10 administrative data. Med Care 2005, 43:1130-1139.

29. Wang CY, Baldwin LM, Saver BG, Dobie SA, Green PK, Cai Y, et al: The contribution of longitudinal comorbidity measurements to survival analysis. Med Care 2009, 47:813-821.

30. Stukenborg GJ, Wagner DP, Connors AF Jr: Comparison of the performance of two comorbidity measures, with and without information from prior hospitalizations. Med Care 2001, 39:727-739.

31. Kleinbaum DG, Klein M: Regression Diagnostics: a self learning text. New York: Springer-Vertag: 2002.

32. Fox J: Regression Diagnostics. London: Sage Publications; 1991.

33. Pan W: Akaike's information criterion in generalized estimating equations. Biometrics 2001, 57:120-125.

34. Rabe-Hesketh S, Skrondal A: Multilevel and longitudinal modeling using strata. College Station: Stata Press; 2005.

35. Begg MD, Parides MK: Separation of individual-level and cluster-level covariate effects in regression analysis of correlated data. Stat Med 2003, 22:2591-2602.

36. Alfandre D: Reconsidering Against Medical Advice Discharges: Embracing Patient-Centeredness to Promote High Quality Care and a Renewed Research Agenda. J Gen Intern Med 2013. doi:10.1007/S11 606-013-2540-z.

doi:10.1186/1472-6963-13-415

Cite this article as: Kraut et al: A population-based analysis of leaving the hospital against medical advice: incidence and associated variables. BMC Health Services Research 2013 13:415.

\section{Submit your next manuscript to BioMed Central and take full advantage of:}

- Convenient online submission

- Thorough peer review

- No space constraints or color figure charges

- Immediate publication on acceptance

- Inclusion in PubMed, CAS, Scopus and Google Scholar

- Research which is freely available for redistribution

Submit your manuscript at www.biomedcentral.com/submit
Biomed Central 